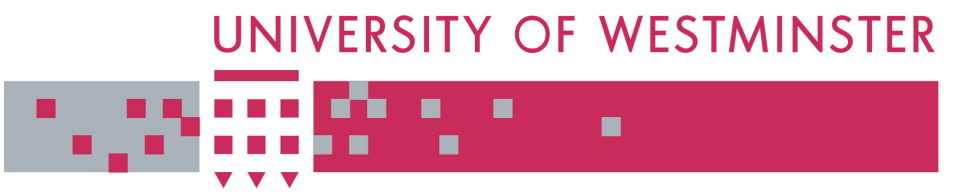

WestminsterResearch

http://www.wmin.ac.uk/westminsterresearch

\title{
Microstrip three-port 4-channel multiplexers using dual-band bandpass filters for wireless applications
}

\section{Damir Zayniyev}

Djuradj Budimir

School of Informatics

Copyright (C) [2008] IEEE. Reprinted from the 2008 IEEE Antennas and Propagation Society International Symposium, Jul 5-11, 2008, San Diego, California. IEEE, Los Alamitos, USA, pp. 1-4. ISBN 9781424420414.

This material is posted here with permission of the IEEE. Such permission of the IEEE does not in any way imply IEEE endorsement of any of the University of Westminster's products or services. Personal use of this material is permitted. However, permission to reprint/republish this material for advertising or promotional purposes or for creating new collective works for resale or redistribution to servers or lists, or to reuse any copyrighted component of this work in other works must be obtained from the IEEE. By choosing to view this document, you agree to all provisions of the copyright laws protecting it.

The WestminsterResearch online digital archive at the University of Westminster aims to make the research output of the University available to a wider audience. Copyright and Moral Rights remain with the authors and/or copyright owners.

Users are permitted to download and/or print one copy for non-commercial private study or research. Further distribution and any use of material from within this archive for profit-making enterprises or for commercial gain is strictly forbidden.

Whilst further distribution of specific materials from within this archive is forbidden, you may freely distribute the URL of the University of Westminster Eprints (http://www.wmin.ac.uk/westminsterresearch).

In case of abuse or copyright appearing without permission e-mail wattsn@wmin.ac.uk. 


\title{
Microstrip Three-Port 4-Channel Multiplexers Using Dual-Band Bandpass Filters for Wireless Applications
}

\author{
D. Zayniyev, and D. Budimir \\ Wireless Communications Research Group, University of Westminster, $115 \mathrm{New}$ \\ Cavendish Street, London W1W 6UW, United Kingdom \\ Email: d.budimir@wmin.ac.uk
}

\section{Introduction}

Fast development of broadband applications in wireless communications caused high interest in compact, low-loss, and light weight bandpass filters. The modern tendency for integration of different wireless standards in one device increased the interest in diplexers/multiplexer to separate channels as well as to provide coexistence of different standards in one circuit in microwave and $\mathrm{mm}$-wave transceivers [1]. Diplexers are three port devices which are commonly used after multi-band or wide band antenna, take two or more frequencies in input port and separate them to two output ports.

Conventional design procedure of the microwave diplexer/multiplexer consists of two steps. First step is design of microwave filters which are usually bandpass/bandstop structures [2] sometimes combined with lowpass/highpass filters. Second step is the combination of developed filters using matching networks [3]. Usually different types of $\mathrm{T}$-junctions are used. The main requirement for any multiplexer is a high isolation between filters and low VCWR on the common port. Very often a connection of different filters to common port causes interaction and degradation of initial transfer characteristics of filters and additional reconfiguration of filters is required.

In this paper a compact three-port four-channel microstrip multiplexer which consists of two dual-band bandpass filters is presented. Two compact dual-band microstrip pseudo-interdigital quasi-elliptical bandpass filters with stepped impedance resonators are used. The first filter has two channels centered at 1.65 and $4.65 \mathrm{GHz}$ and the second filter has two channels centered at 2.5 and $6.9 \mathrm{GHz}$.

\section{Filter and Diplexer Design}

Fig. 1 (a) illustrates the layout of stepped impedance resonator which is half wavelength resonator with two sections of low impedance on both sides and the section with high impedance in the middle. This structure also can be considered as composed two $\lambda \mathrm{g} / 4$ stepped impedance resonators which is shown on Fig. 1(b) as midpoint at resonance can be represented as a short circuit. 
a)

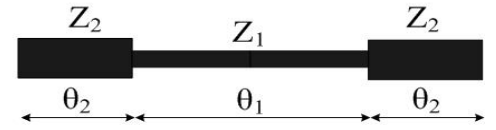

b)

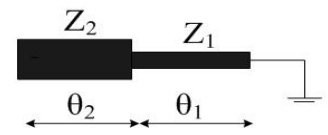

Fig. 1. Structure of $\lambda g / 2$ SIR (a) and grounded $\lambda g / 4$ SIR (b)

The resonance condition can be described as [4]:

$$
\tan \theta_{1} \cdot \tan \theta_{2}=R
$$

where $R$ is the ratio of low impedance to high impedance:

$$
R=\frac{Z_{1}}{Z_{2}}
$$

which is used to tune the fundamental resonance and higher order resonances as the ratio of first spurious resonance fs to fundamental resonance $\mathrm{f}_{0}$ is equal to:

$$
\frac{f_{s}}{f_{0}}=\frac{\pi}{\tan ^{-1} \sqrt{R}}-1
$$

Thus for design of dual-band filter in case when the first spurious resonance should be closer to fundamental resonance higher $\mathrm{R}$ should be used.

Fig. 2. illustrates the layout of the proposed microstrip pseudo-interdigital stepped impedance bandpass filter. This filter is modified bandpass proposed in [5] filter with introduced stepped impedance resonators

PORT1
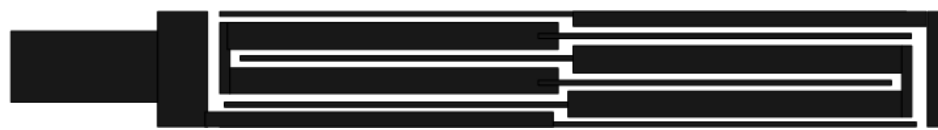

PORT2

Fig.2. Layout of microstrip dual-band bandpass filter

The centre frequency is defined by the length of resonators. The second pass band of filter can be regulated using different ratio $\mathrm{R}$. For designed filters $\mathrm{R}$ was chosen to be $\mathrm{R}=0.86$ as the higher $\mathrm{R}$ the higher losses due to discontinuities between resonators. Dualband filter was designed to have first pass band centered at $2.5 \mathrm{GHz}$ and the second pass band at $6.9 \mathrm{GHz}$. The bandpass filter was simulated by using Agilent ADS Momentum [6] simulator and S-parameter responses are shown in Fig. 3. 


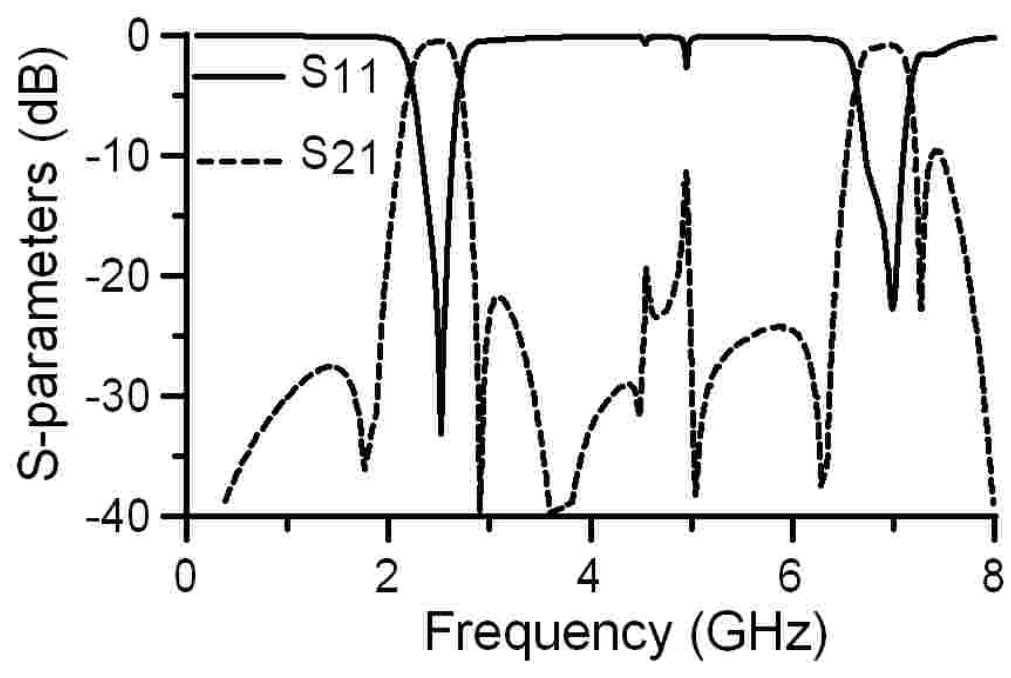

Fig. 3. Simulated S-parameters of the dual-band bandpass filter

In order to develop a diplexer a second dual-band bandpass filter with pass bands at 1.65 and $4.65 \mathrm{GHz}$ respectively. The structure of filter is the same just the length of stepped impedance resonators was increased. In order top decrease the losses on matching circuit both filters were connected to the same feeding line as it is shown in the Fig. 4.

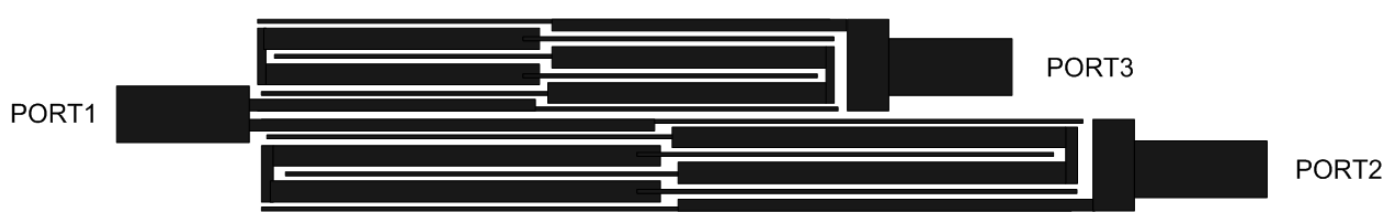

Fig. 4. Layout of proposed microstrip three-port multiplexer

The microstrip three-port multiplexer was simulated using Agilent ADS Momentum simulator and S-parameter responses are shown in Fig. 5. This combination also reduces the total size of diplexer 1 which is $37 \times 8.5 \mathrm{~mm}$. For our design, a Rogers RT/Duroid 5880 material with a substrate thickness of $0.508 \mathrm{~mm}$ and a dielectric constant of 2.2 was used. According the simulation multiplexer has very good transmission and reflection characteristics on both channels of the first pass bands of filters with minor distortions on the second channels of filters. The isolation between channels is about $20 \mathrm{~dB}$.

As it was predicted the integration of two filters caused the distortion of characteristics and appearance of additional picks at about 3 and $6 \mathrm{GHz}$. The improvement of performance of multiplexer is under further investigation. Additional transmission zeros can be introduced to suppress unwanted picks implementing spur lines [7] in the stepped impedance resonators or using other convenient methods [8]. 


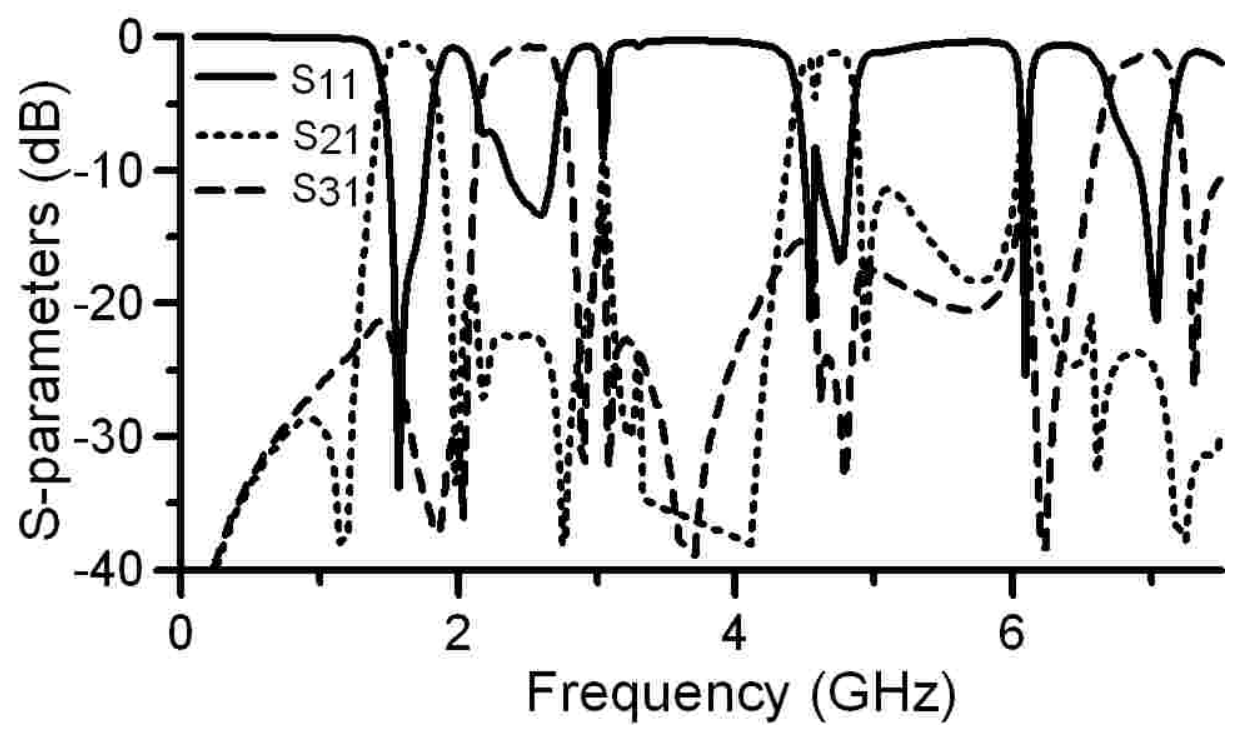

Fig. 5. Simulated S-parameters of the microstrip diplexer.

\section{Conclusion}

This paper presents a compact microstrip three-port 4-channel multiplexer using dualband bandpass filters with good transmission and reflection characteristics on each channel. Proposed multiplexer configuration can be used for design of very compact multiplexer for broadband wireless applications using super compact microstrip pseudointerdigital quasi-elliptical bandpass filters with or without stepped impedance resonators. The size of the proposed circuit is reduced. The improvement of the performance of multiplexer through introduction of additional transmission zeros is under investigation.

\section{References:}

[1] M-I. Lay and S-K Jeng, "A microstrip three-port and four-channel multiplexer for WLAN and UWB coexistence". IEEE Trans. Microwave Theory Tech., vol. 53, no 10, pp.3244-3250, October 2005

[2] G. L. Matthaei and E. G. Cristal, "Multiplexer channel-separating units using interdigital and parallel- coupled filters. IEEE Trans. Microwave Theory Tech., vol. MTT-13, pp.328-334, May 1965

[3] G. L. Matthaei, L. Young and E. M. Jones, Microwave Filters, Impedance-Matching Networks and Couplinf Structures, Artech House, 1980.

[4] M. Sagawa, M. Makimoto, and S. Yamashita, "Geometrical structures and fundamental characteristics of microwave stepped-impedance resonators," IEEE Trans. Microwave Theory \& Tech., vol. 45, no. 7, pp. 1078-1085, July 1997

[5] D. Zayniyev, D. Budimir, G. Zouganelis, "Microstrip filters and diplexers for WiMAX applications," Antennas and Propagation International Symposium, 2007 IEEE, pp. 1078-1085, June 2007

[6] Agilent EEsof, http://eesof.tm.agilent.com

[7] Bates, R.N.: 'Design of microstrip spur-line band-stop filters', IEE J. Microw. Opt. Acoust., 1977, 1, pp. 209-214

[8] D. M. Pozar, Microwave Engineering. New York: Wiley, 1997. 